\title{
7 \\ DAKWAH HARMONI KOMUNITAS: \\ Studi Transformasi Identitas Kampung Muslim Dayak di Desa Semabi, Kecamatan Sekadau Hilir, Kabupaten Sekadau Kalimantan Barat
}

\author{
Abdul Halim1, Baiti Rahmawati², Roisul Umam³ \\ UIN Sunan Ampel Surabaya \\ halim@uinsby.ac.id1 baitirahma02@gmail.com ${ }^{2}$, Roisptk1306@gmail.com³
}

\begin{abstract}
This study reviews the Dayak ethnicity as an exotic ethnicity with a unique interior image. They are accustomed to 'hunting human heads for marriage plots'. Traditions like this are considered as an obligation to avoid danger and disaster, and become a symbol of power and manliness. However, the practice of 'head hunting' only applies when Islam has not touched the theology of the Dayak community with ancestral religion in the past. This study focuses on the struggle of the Dayak Senganan and Malays in the villages of Semabi, Sekadau Hilir, Sekadau, West Kalimantan, which relates to the stigma that, by embracing Islam it means revoking the 'worthiness' identity. To illustrate the transformation of Dayak Wealth identity The methodology used in this study is the ethnographic method. The term 'Wealth' is derived from the word 'right' which means the transition from left to right, namely by embracing Islam. Findings from this study indicate that the key to inter-citizen harmony is supported by the strength of harmony between religious elites and also local cultural elites, and the role of shared awareness to coexist becomes a benchmark of harmonization. The power of harmony built by these two elite figures has produced transformative propaganda based on tradition.
\end{abstract}

Keywords: Harmony, transformation, identity, Dayak Senganan.

\begin{abstract}
Abstrak: Studi ini mengulas tentang etnisitas Dayak sebagai etnis yang eksotik dengan citra pedalaman yang unik. Mereka terbiasa 'berburu kepala manusia untu makar menikah'. Tradisi seperti ini dianggap sebagai sebuah kewajiban agar terhindar dari bahaya dan musibah, serta menjadi suatu simbol kekuasaan dan kejantanan diri. Namun, kebiasaan 'berburu kepala' hanya berlaku ketika Islam belum menyentuh sisi teologi masyarakat Dayak dengan agama leluhur pada masa lalu. Kajian ini berfokus pada pergumulan Dayak Senganan dan Melayu di desa Semabi, Sekadau Hilir, Sekadau, Kalimantan Barat yang berkaitan dengan stigma bahwa, dengan memeluk Islam berarti tercabutlah identitas 'kedayakan'. Untuk menggambarkan transformasi identitas Dayak Senganan Metodologi yang dipakai dalam penelitian ini adalah metode etnografi. Term 'Senganan' berasal dari kata 'kanan' yang diartikan peralihan dari kiri ke kanan, yaitu dengan jalan memeluk agama Islam. Temuan dari penelitian ini menunjukkan bahwa kunci kerukunan antar-warga didukung dengan kekuatan harmoni antara elit agama dan juga elit budaya lokal, serta peran kesadaran bersama untuk hidup berdampingan menjadi tolak ukur harmonisasi. Kekuatan harmoni yang dibangun oleh dua tokoh elit inilah yang menghasilkan dakwah transformatif yang berbasis pada tradisi.
\end{abstract}

Kata Kunci: Harmoni, transformasi, identitas, Dayak Senganan. 


\section{A. Pendahuluan}

Indonesia terdiri dari 34 provinsi yang terletak di lima pulau besar dan empat kepulauan. Salah satunya pulau Kalimantan yang terbagi menjadi Kalimantan Barat, Kalimantan Tengah, Kalimantan Selatan, Kalimantan Timur, dan Kalimantan Utara. Menurut data BPS tahun 2018, prosentase terhadap jumlah pulau yang berada di Kalimantan Barat dengan ibu kota provinsi yang terletak di Pontianak sebanyak 243 pulau; 2 kota; 12 Kabupaten; 174 kecamatan; 2132, dan 4932, 5 penduduk pada tahun 2017.133

Salah satu suku yang eksis dan menjadi suku asli di Kalimantan adalah suku Dayak. Di dalamnya terdapat keragaman yang besar antara suku satu dengan suku lainya dilihat dari segi bahasa, kesenian, upacara adat, dan juga arsitektur rumah. ${ }^{134}$ Secara harfiyah, kata Dayak berarti orang yang berasal dari pedalaman atau gunung, kata Dayak juga merupakn nama kolektif bagi kelompok suku di Kalimantan. Sebagian besar orang Dayak mempraktikkan peladangan berpindah-pindah. Pada umumya mereka bermukim di sepanjang sungai di pedalaman Kalimantan, oleh karenanya mereka disebut berbudaya sungai (riverin culture) ataupun hulu. Dalam pola tradisi, orang Dayak sangat berpegang teguh pada hukum adat atau adat istiadat tradisional nenek moyang yang diwariskan turun-temurun. ${ }^{135}$

Dalam banyak studi antropologis, Dayak disebut sebagai masyarakat/etnis asli Kalimantan yang sering diidentikkan sebagai kelompok yang eksotik; terkenal dengan citra pedalaman dan terasing; terbiasa berburu kepala manusia; tinggal di rumah panjang (lamin); menggunakan parang (mandau) dan sumpit (tulup); bermata sipit dengan telinga (cuping panjang), berpindah-pindah (nomaden); lekat dengan tarian dalam upacara adat; dan menganut agama tradisional yang disebut 'Kaharingan'136

Dalam aspek religuisitas, Dayak dicitrakan sebagai komunal yang animis. Bahkan kesan ini kerap digunakan untuk menunjuk identitas Dayak. Suku Kutai dan Banjar yang masuk Islam tidak lagi diidentifikasi sebagai Dayak karena tidak lagi menganut agama tradisional. Fenomena identifikasi seperti ini kemudian menggiring pemahaman bahwa secara kolektif menunjuk Dayak sebagai orang-orang non-muslim dan non-Melayu yang merupakan penduduk asli Kalimantan. Mereka yang masuk Islam kemudian disebut 'halo' dan seolah keluar dari identifikasi sebagai orang Dayak. ${ }^{137}$ Konstruksi Dayak sebagai non-muslim dan Non Melayu seperti ini memaksa sekelompok orang untuk melepas identitas 'kedakayannya' dan meletakkan etnisitasnya menjadi Kutai, Paser, Banjar, maupun Melayu. 138

Melayu asli Kalimantan (Kalimantan Barat) memiliki pertalian erat dengan orang-orang Dayak secara sejajar (horizontal) berupa hubungan kekerabatan maupun secara tegak lurus (vertical) melalui perkawinan campur (intermarriage). Dalam konteks ini, Dayak dan Melayu dianggap bersaudara karena Dayak yang masuk Islam menyebut dirinya sebagai Melayu. Menurut cerita rakyat, para pendatang ${ }^{139}$ mendesak penduduk asli yang berdiam diri di tepi laut dan tepi sungai Kapuas dengan berbagai macam sebab dan akhirnya terdesak ke hulu, sejak itulah orang Dayak disebut sebagai orang 'Hulu'. Sedangkan suku Melayu pada umumnya terpisah dengan suku Dayak. Hal ini disebabkan oleh agama, pergaulan dan cara hidup yang dijalani

\footnotetext{
133 BPS-Statistic Indonesia, Statistik Indonesia: Statistical Yearbook of Indonesia 2018

${ }_{134}$ Masri Singarimbun, Penduduk dan perubahan (Yogyakarta: Pustaka Pelajar, 1996), h. 258-259

135 Lahajir, Etnoekologi Perladangan Orang dayak Tunjung Linggang: Etnografi Lingkungan Hidup di Dataran Tinggi Tunjung (Yogyakarta: Galing Printika, 2001), h. 4

136 Ahmad Muthohar AR, Islam Dayak: Diaektika Identitas Dayak Tidung di Kalimantan (Semarang: Fatawa Publishing, 2015), h.1

137 Michael Hitchoock, Victor T. King, Tourism in South East Asia (New York: Roudledge, 1993), h.29

138 Anis Masykur, Resistensi atas Islamisasi di Kerajaan Kutai kartanegara, dalam Jurnal Istiqro', Vol 1 (Jakarta: Depag RI, 2007)

139 Kedatangan orang-orang asing ini secara tidak langsung mendesak suku asli semakin masuk ke pedalaman, kemudian mereka mendiami daerah yang ditinggalkan oleh suku Dayak. Semakin lama, penduduk aslipun banyak yang terpengaruh dengan cara hidup para pendatang dan akhirnya masuk Islam, proses ini dikenal dengan masok Melayu atau turun Melayu
} 
olehnya. Pada dasarnya, suku Melayu adalah bangsa pendatang dari Jazirah Malaka atau Semenanjung Melayu. 140

Keberadaan warga muslim Dayak tidak terlalu menonjol karena kurangnnya publikasi maupun karena peralihan identitas. Sebagaimana penelitian yang dilakukan oleh Hermansyah pada masyarakat Muslim Kanayatn Dayak di Kalimantan Barat, ia menyatakan bahwa masyarakat Muslim maupun non-Muslim dapat hidup berdampingan. Dari segi identitas etnik, penduduk yang telah memeluk Islam tetap dianggap sebagai orang Dayak atau orang 'Ahe' atau 'Kanayatn'. Bahkan yang lebih unik lagi dalam satu keluarga yang tinggal di rumah Apin misalnya, paling tidak ada tiga agama yang dipeluk oleh anggota keluarga. Apin dan istrinya memeluk Islam, ibu dan beberapa adiknya penganut Katolik taat, seorang adik beragama protestan, dan satu adik lakilakinya menganut agama tradisional. ${ }^{141}$

Sebagaimana muslim Dayak di Kanayatn, muslim Dayak di Semabi juga hidup berdampingan dengan pemeluk agama lain. Bahkan ketua adat Dayak di sana juga beragama Islam. Persaudaraan dan kerukunan yang mewarnai ruang publik di Kalimantan Barat ini tidak terlepas dari konteks identitas dan etnisitas. Bahan yang bisa digunakan untuk membentuk identitas dapat terkait dengan kondisi sosial, geografis, etnik, gender maupun kebangsaan. Jika berkaitan dengan kelas sosial memuncukan identitas kelas elite dan kelas biasa; berkaitan dengan agama memunculkan identitas muslim, kristiani, konghucu dan lain sebagainya. Berkaitan dengan georgrafi memunculkan identitas orang Pontianak, orang Ulu, Sambas, orang darat dan lainnya. ${ }^{142}$

Dalam konteks Identitas, isu bipolaritas Dayak-Melayu menjadi pembicaraan yang hangat di ruang publik. Salah satu kepercayaan lokal yang berafiliasi dengan agama Islam yang hendak dipaparkan dalam tulisan ini adalah Islam pada masyarakat Dayak yang berdomisili di desa Semabi, Sekadau Hilir, Sekadau, Kalimantan Barat. Mayoritas warga dusun ini telah memeluk Islam sampai 4 generasi melalui pernikahan silang antara ketua Adat antar ras Melayu Islam dengan putri adat Dayak Kristen. Dari sekian banyak sub suku Dayak di Kalimantan Barat, kajian ini berfokus pada pergumulan Dayak Senganan dan Melayu di Semabi yang berkaitan dengan stigma bahwa, 'dengan memeluk Islam berarti tercabutlah identitas kedayakan'.

\section{B. Kerangka Teori}

Identity adalah kata dari bahasa Inggris yang berasal dari bahasa latin 'identidem' atau 'idem' yang berarti kesamaan atau kesinambungan. ${ }^{143}$ Mesthire dan Tabouret-Keller menyebutkan bahwa identitas merupakan ciri yang dimiliki seseorang atau sesuatu sebagai pengenal atau pembeda antara satu dengan yang lain. ${ }^{144}$ Setidaknya ada dua pendapat yang muncul terkait dengan identitas, yaitu: (1) identitas sebagai satu ciri beku atau tidak berubah bahkan melekat dan tidak bisa diganti; serta (2) identitas sebagai ciri yang cair (fluid) yang dapat berubah sesuai kepentingan. Dengan identitas, identifikasi dapat dibangun atas asal-usul atau karakteristtik bersama seseorang atau kelompok melalui pelabelan atas status seseorang. ${ }^{145}$ Dengan kata lain, identitas dapat diartikan sebagai hal-hal yang harus dimiliki seseorang dalam proses interaksi sosial.

Identitas (identity) secara sederhana dapat dipahami sebagai cirri-ciri atau keadaan khusus seseorang. Jika ditarik ke ranah yang lebih luas, semisal masyarakat, identitas berarti segala hal

140 Ita Syamtasiyah Ahyat, Dinamika dan Pengaruh Budaya Melayu di Kalimantan Barat, makalah dipresentasikan pada "Prosiding the $4^{\text {th }}$ Conferece on Indonesian Studies: Unity, Diversity, and Future"

${ }^{141}$ Hermansyah, Islam dan Toleransi Beragama dalam Masyarakat Muslim Kanayatn Dayak di Kalimantan Barat, dalam jurnal Islamica, Vol. 7, N. 02 (2013), h. 340-359

142 Yusriadi, Identitas Dayak dan Melayu di Kalimantan Barat, dalam jurnal Handep, Vol. 1, No. 2 (Juni 2018), h. $1-16$

${ }^{143}$ Shamsul A. B., Identiti dan Etnisiti: Tinjauan Teoretis, dalam Yusriadi dan Haitami Salim, ed, Prosiding Kolokium Dayak Islam di Kalimantan Barat (Pontianak: STAIN Ppontanak-FUI-MABM, 2001), 13-14

144 Ibid., h. 165-168

${ }^{145}$ Stuart Hall and Paul Du Gay, Ed, Questions of Cultural Identity (London: Sage Publication, 2003), h. 2 
yang yang menjadikan suatu masyarakat dikenal, dengan kekhasan yang membedakan orang tersebut dengan orang lain.

Sosiolog Richard Jenkins (1996) memandang identitas kolektif didasari oleh interaksi dialektik dari proses definisi internal dan eksternal. Di satu sisi, individu harus dapat membedakan diri dari yang lain dengan mengacu pada kriteria komunitas dan rasa memiliki bersama dalam subkelompok mereka. Di sisi lain, proses identifikasi internal ini harus diakui oleh orang luar agar muncul identitas kolektif yang obyektif. ${ }^{146}$ Proses kategorisasi identitas dibingkai dari hubungan masa lalu, masa kini, dan masa depan melalui dimensi kognitif dan emosional.

Identitas mengikat seseorang dengan kelompok mana ia berada, melalui pembentukan keanggotaan dalam kategori sosial yang sama. Identitas juga dianggap untuk membangun keunikan seseorang dengan fungsi ganda: (1) diidentifikasi dengan orang lain dalam posisi struktur; dan (2) diindividuasikan atau dibedakan dari mereka. ${ }^{147}$

Peter L. Berger \& Thomas Luckmann banyak menjelaskan tentang pembacaan masyarakat sebagai kenyataan sosial. ${ }^{148}$ Dengan teorinya, 'Sosiologi pengetahhuan', ia menjelaskan bahwa dalam kehidupan sehari-hari, masyarakat harus dilihat sebagai kenyataan atau fakta. Lebih jauh juga dijelaskan bahwa fenomena modernitas merupakan fenomena yang memengaruhi pembentukan identitas. Dalam penelitian ini ada dua identitas berbeda yang dipakai oleh masyarakat Semabi dalam hal religiusitas. Agama dijadikan pembeda antara Dayak dan melayu. Dayak Identik dengan agama Kristen dan Melayu identik dengan Islam, bahkan agama dianggap sebagai penentu identitas kesukuan.

\section{Metodologi}

Penelitian ini menggunakan metode etnografi ${ }^{149}$ dengan memainkan dua peranan, yaitu: peneliti sebagai penjaring data sosial; sekaligus sebagai "participant observer, " yang berinteraksi dengan masyarakat. Dengan cara ini peneliti berupaya memahami aspek yang diteliti sebagaimana masyarakat memahaminya di samping menggunakan sudut pandang sendiri dalam memaknai kondisi masyarakat. 150 Tulisan ini bersifat kualitatif dan etnografis, karena data-data mengenai dinamika transformasi identitas dan harmoni Dayak Senganan diperoleh dengan cara participation Observation (observasi pengikutsertaan) dan wawancara terbuka-mendalam.

Data-data mengenai dinamika identitas dan harmoni ini dikumpulkan berdasarkan pengamatan langsung (direct observation), mencatat, dan merekam data dari objek yang diamati. Kemudan dilanjutkan dengan membuat deskripsi dan analisis tertulis tentang objek yang dikaji151. Dengan kata lain, pengungkapan dinamika transformasi identitas dan harmoni Dayak Senganan tersebut dipandang dan diuraikan secara emik (masyarakat yang diteliti), dan etik (peneliti).

Penelitian ini bersifat desktiptif-eksploratif. Bersifat deskriptif karena bertujuan menggambarkan secara lengkap mengenai kehidupan orang Semabi dan transformasi identitas Dayak Senganan. Juga bersifat eksploratif karena bertujuan untuk memeroleh pengetahuan yang luas tentang masyarakat Dayak di Semabi sebagai dasar dari kajian selanjutnya mengenai kelompok masyarakat tersebut. Selain data primer, data sekunder juga dikumpulkan dalam bentuk apapun yang berhubungan dengan topik, antara lain dari buku-buku dan hasil penelitian yang terkait.

\footnotetext{
146 Jonathan H. Turner, Handbook of Sociological Theory (New York: Springer, 2006), h. 172

147 Lee Freese and Peter J. Burke, Person, Identities, and Social Interaction (London: JAI Press, t.t), 5

148 Peter L. Berger \& Thomas Luckmann, The Social Construction of Reality, dalam Hasan basari (terj), Tafsir Sosial atas kenyataan: Risalah tentang Sosiologi pengertahuan (Jakarta: LP3ES, 1990), h. 32

${ }^{149}$ Secara leksikal, kata 'etnografi' (ethnography) diserap dari bahasa Latin 'ethnos' (berarti 'bangsa') dan 'graphein' (berarti 'catatan'). Dari makna generik ini etnografi dapat diartikan sebagai catatan atau laporan tentang tentang suatu masyarakat tertentu.

150 James P. Spardley, Metode etnografi, Terj. Misbah Elizabeth (Yogyakarta: Tiara Wacana, 1997), h. 30

${ }^{151}$ Agus Salim, Teori dan paradigm Peneliatian Sosial: Buku Sumber untuk Penelitian, Edisi 2 (Yogyakarta:

Tiara Wacana, 2006), h. 129
} 
Alasan pemilihan lokasi penelitian di Semabi adalah: (1) Semabi adalah kampung Dayak; (2) penduduk kampung bersifat heterogen (pribumi dan pendatang); (3) terdapat beragam agama (Islam, Kristen: Katolik-Protestan, dan kepercayaan tradisional (kaharingan); (4) Mayoritas penduduk Desa Semabi adalah pemeluk agama Islam.

James Spradley ${ }^{152}$ memaparkan langkah-langkah etnografi sebagai alur maju bertahap (Developmental Research Sequences-DRS) yang terdiri dari dua belas langkah ${ }^{153}$, yang disepadankan dengan tiga tahapan utama, yaitu dapat disamakan dengan tahap pengumpulan data, tahap proses analisis data, dan tahap penulisan laporan etnografi.

\section{Deskripsi Masyarakan Semabi}

Kabupaten sekadau ${ }^{154}$ terletak di antara Kabupaten Sanggau dan Kabupaten Sintang Provinsi Kalimantan barat dengan batas wilayah Utara dan Timur dengan kabupaten Sintang; Selatan dengan kabupaten Ketapang; dan Barat dengan Kabupaten Sanggau. Secara topografi, kondisi alam kabupaten Sekadau ${ }^{155}$ merupakan daratan dan perbukitan dengan tiga sungai utama yang melintas di wilayah ini antara lain: Sungai Kapuas, Sungai Sekadau, dan Sungai Belitang.

Dalam rangka pengembangan dan pemekaran wilayah administratif, pada tanggal 18 Desember 2003, Sekadau diresmikan menjadi daerah otonom baru dengan tujuh Kecamatan, antara lain: Kecamatan Sekadau Hilir, Kecamatan Sekadau Hulu, kecamatan Nanga Taman, Kecamatan Nanga Mahap, Kecamatan Belitang Hilir, Kecamatan Belitang, dan Kecamatan Belitang Hulu. ${ }^{156}$

Sekadau Hilir merupakan salah satu kecamatan di kabupaten Sekadau. Masyarakat kecamatan ini mayoritas memeluk agama Islam, dengan sub suku bernama Dayak Senganan dengan 17 desa, salah satunya adalah desa Semabi yang memiliki empat dusun, Yaitu: Semabi, Ensanguk, Tapang Jaya dan Tapan Sepati. Nama Semabi sediri merupakan kepanjangan dari 'Sekelompok Masyarakat Beragama Islam' yang disingkat menjadi 'SEMABI'.Menurut penuturan turun temurun oleh Jamri157, sejarah masuknya Islam di Semabi dibawa oleh 3 tokoh keraton di desa Munggu seberang sungai di Semabi, mereka adalah Gusti Kayut, Gusti Masyhud, dan Gusti Kamal. Dari ketiga pangeran ini, Gusti Kamal- lah yang berperan dalam menyebarkan Islam dengan menikahi putri tokoh suku adat Kodah. ${ }^{158}$

Dalam hal kesejahteraaan, Desa Semabi menjadi lumbung pangan terbanyak di kecamatan Sekadau Hilir kabupaten Sekadau dengan jumah 5, 83 Ton pada tahun 2018159. Produksi beras

\footnotetext{
152 Ibid., ...h. 130

153 yaitu: (1) menetapkan informan; (2) mewawancarai informan; (3) membuat catatan etnografis; (4) mengajukan pertanyaan deskriptif; (5) menganalisis hasil wawancara; (6) membuat analisis domain; (7) mengajukan pertayaan struktural; (8) membuat analisis taksonomik; (9) mengajukan pertanyaan kontras; (10) membuat analisis komponen; (11) menemukan tema-tema; (12) menulis laporan etnografi.

${ }^{154}$ Bupati Sekadau adalah Rupinus, SH., M.Si (periode 2016-2021)

155 Menurut laporan BPS (2018), Nama Sekadau sendiri merupakan nama sebuah pohon kayu 'batang $a d a u$ '. Pohon ini merupakan sejenis kayu belian (kayu besi) yang banyak tumbuh di sepanjang sungai dan hutan Sekadau. Sebelum adanya perubahan status menjadi kabupaten, Sekadau pada mulanya merupakan wilayah kerajaan atau 'kewedanan', sebuah nama benua yang disebut dengan benua Sekado, yakni kumpulan beberapa desa besar di kabupaten Sanggau. Raja pertama Sekadau adalah Pangeran Engkong yang memiliki tiga putra, yakni pangeran Agong, Pangeran Kadar, dan Pangeran Senarong. Setelah pangeran Engkong mangkat, tampuk kekuasaan dilanjutkan oleh putra keduanya, yaitu Pangeran Kadar lalu dilanjutkan oleh Pangeran Suma hingga Pangeran Abang Todong yang bergelar Sultan Anum. Makam Sultan Anum terletak di desa Mungguk (Sungai Barak) kecamatan Sekadau Hilir dan menjadi warisan cagar budaya di kabupaten Sekadau.

156 Profil daerah Kabupaten Sekadau per Juli 2017-Juni 2018, h. 25-35

${ }^{157}$ Adalah kepala desa dan Guru SD 07 Semabi, warga pribumi Semabi berusia 34 tahun.

158 Menurut Jamri, Kodah adalah nama daerah sebelum disebut sebagai Semabi.

159 Dinas Ketahanan Pangan, pertanian, dan Perikanan Kabupaten Sekadau, dalam Profil daerah Kabupaten Sekadau per Juli 2017-Juni 2018, h. 56
} 
yang meningkat dari tahun ke tahun mendapat apresiasi dari pemerintah daerah, dalam pekan ini wakil Bupati Sekadau 160 menghadiri panen raya 'rendengan' milik kelompok tani Sepayang Permai di desa Semabi. ${ }^{161}$ Dengan mata pencaharian berladang/bertani inilah Islam kemudian dikembangkan dengan luwes melalui pendekatan ekonomi kemasyarakatan.

\section{E. Hasil dan Pembahasan}

\section{Transformasi Identitas Dayak dan Melayu}

Secara umum, pengertian transformasi budaya adalah perubahan konsep, bentuk, fungsi, dan sifat budaya untuk menyesuaikan dengan konstelasi dunia. Jadi, sebuah transformasi merupakan sebuah perubahan yang direncanakan dan disengaja untuk tujuan tertentu. ${ }^{162}$ Transformasi budaya dan transformasi sosial memiliki perbedaan yang mendasar. Transformasi sosial meliputi perubahan dalam masyarakat yang meliputi: perbedaan usia, tingkat kelahiran, dan penurunan rasa kekeluargaan anggota masayarakat sebagai akibat terjadinya arus urbanisasi dan modernisasi. Sedangkan transformasi budaya menyangkut banyak aspek kehidupan seperti: kesenian, ilmu pengetahuan teknologi, bahkan aturan hidup berorganisasi, dan filsafat. 163

Hilmes dan Moore (1998), transformasi sosial memiliki tiga dimensi, 164 yaitu: (a) struktural, mengacu pada perubahan dalam bentuk struktur masyarakat, menyangkut perubahan dalam peranan, munculnya peranan baru, perubahan dalam struktur kelas sosial, perubahan dalam lembaga sosial; (b) dimensi kultural, mengacu pada perubahan kebudayaan dalam masyarakat. Perubahan ini meliputi: pertama, inovasi. Inovasi budaya mengacu pada komponen internal yang memunculkan perubahan sosial dalam suatu masyarakat. Kebutuhan masyarakat yang semakin kompleks memaksa individu untuk berpikir kreatif untuk mencapai perubahan. Inovasi kebudayaan yang paling mudah ditemui adalah munculnya teknologi baru.

Kedua, Difusi. Difusi merupakan komponen eksternal yang mampu menggerakkan terjadinya perubahan sosial. Pertemuan budaya memicu perubahan kebudayaan dalam masyarakat yang 'menerima' unsur-unsur budaya tersebut. Ketiga, intergrasi. Integrasi merupakan wujud perubahan budaya yang disebabkan penyatuan unsur-unsur kebudayaan yang saling bertemu untuk kemudian memunculkan kebudayaan baru sebagai hasil penyatuan unsur-unsur budaya tersebut.

Pertemuan kebudayaan dalam penelitian ini digambarkan dengan bertemunya budaya Dayak dan Melayu. Istilah Dayak digunakan pertama kali oleh Rademaker tahun 1790 untuk menyebut komunitas pribumi non-Islam. Istilah ini sejajar dengan sebutan Melayu bagi penduduk yang beragama Islam. Dahulu, bagi pribumi yang tidak memeluk Islam, identitas Dayak dianggap sebagai suatu yang menghina dengan konotasi yang negatif, sehingga penduduk pribumi menerima sebutan itu dengan setengah hati. Mereka lebih suka disebut 'Daja' atau 'Daya' karena dianggap lebih cocok dan menggambarkan suatu kekuatan bangkit dan semangat. Hingga tahun 1980 identitas Dayak mulai sering digunakan oleh orang pribumi, pada masa itu istilah Dayak menjadi pengikat untuk bangkit dari keadaan marjinal. Bahkan pada tahun 1990, istilah Dayak di Kalimantan Barat mulai dipakai oleh kalangan pribumi yang memeluk Islam. ${ }^{165}$

Lain halnya Dayak, di Kalimantan Barat identitas Melayu digunakan dalam konteks positif sehingga mudah diterima oleh beberapa kalangan, bahkan dalam konteks sosial-keagamaan,

\footnotetext{
160 Wakil bupati sekadau bernama Aloysius, SH., M.Si periode 2016-2021

161 Yuni Kurniyanto, Sekadau targetkan Swasembada Beras, (Januari 3, 2019), dalam https://equator.co.id diakses pada 08 September 2019

162 Johanes Mardimin, ed, Jangan tangisi Tradisi: Transformasi Budaya menuju Masyarakat Indonesia Modern (Yogyakarta: Kasinius, 1994), h. 13

163 Nanang Martono, Sosiologi Perubahan Sosial: Perspektif Klasik, Modern, Postmodern, dan Psikolonial, edisi Revisi, Cet. 4 (Jakarta: Rajawali Press, 2016), h. 12

164 Nanang Martono, Sosiologi Perubahan Sosial.., h. 6

165 Yusriadi, Identitas Dayak dan Melayu di Kalimantan Barat, dalam jurnal Handep, vol. 1, No. 2 (2018), h. 1-16
} 
seorang muallaf akan disebut sebagai orang Melayu atau 'turun Melayu.' Islam dibawa oleh kesultanan Malaka di Johor yang memperluas kekuasaannya di Borneo lalu menduduki kesultanan Brunei. Keberadaan suku Melayu tidak terlepas dari masa keemasan kesultanan Melayu yang tersebar di pulau Kalimantan mulai dari kesultanan Pasir, Pontianak, Bulungan dan sebagainya. ${ }^{166}$

\section{Dinamika Transformasi menuju Harmoni}

Kalimantan Barat masih menjunjung tinggi konsep kebhinekaan dan memegang prinsip kebersamaan, serta membangun relasi antar masyarakat dalam hal budaya, seperti membaur bersama dalam upaya adat dan ritual keagamaan. Upacara adat Gawai Dayak atau biasa disebut pekan Gawai merupakan ritual yang dilaksanakan oleh masyarakat Dayak sebagai bentuk syukur kepada Jubata atau Tuhan atas hasil panen yang diperoleh oleh masyarakat. Selain fungsi spiritual, Gawai Dayak juga memiliki fungsi sosial yang bertujuan untuk meningkatkan rasa persaudaraan dan gotong royong antar-warga yang terlibat dalam pelaksanaan upacara adat tersebut.167

Dalam hal beragama, Suku Dayak memberi kebebasan bagi para pemeluknya. Tidak ada paksaan dalam agama selama tidak menimbulkan perpecahan. Kunci kerukunan antar-warga didukung dengan kekuatan harmonisasi yang tertera dalam komposisi administrasi pemerintahan desa dengan: kepala desa (Jamri, pribumi Semabi beragama Islam); sekretaris desa (Bumbun, beragama Katolik); bendahara (Amit, beragama Islam); kasi umum (Zakaria, beragama Kristen Protestan); dan lainnya. ${ }^{168}$

Secara kultural, pola interaksi Islam dengan budaya lokal mulai terpublikasi dari kiprah seorang muballigh yang datang dari Jawa Timur. Ia dikenal dengan panggilan Ustadz Syarif Hidayatullah, berusia 33 tahun dan merupakan alumni pondok pesantren Genggong Kraksan Probolinggo. Pada tahun 2014 ia mendapat tugas kedinasan dari pemerintah sebagai penyuluh pertanian dari lembaga BAZNAZ, 'zakat community development' untuk pembangunan masyarakat. Sebagaimana kesehariannya sebagai pendakwah, ia menerapkan 'ngaji pasaran' (mengaji Islam setiap satu minggu sekali) yang mulai aktif setelah satu tahun keberadaanya di Semabi.

Pada pertengahan 2017, secara tidak langsung ia telah mengembalikan kultur Ahlus Sunnah wal Jamaah yang telah lama diikuti oleh Muslim Semabi, yaitu mulai abad ke-16. Tidak hanya itu, ia juga melakukan pendekatan dengan menggandeng ketua adat dalam hal ini Bang Aang Junaidi untuk mendukung kegiatan dakwahnya. Ketua adat memiliki otoritas yang tinggi sebagai tokoh yang disegani dalam etnis ini sehingga dapat memberikan pengaruh yang signifikan dalam pelestarian Islam.

Sebagaimana faham nahdliyin, faham Islam lainnya juga sempat masuk ke Semabi, di antaranya ada faham yang berusaha memurnikan ajaran Islam tanpa tercampur dengan budaya lokal, yakni Jamaah Tabligh. Namun dalam interaksinya di Semabi, Islam Jamaah cenderung tidak memiliki pengaruh besar dalam penyebarannya. Tidak hanya Islam, misi Kristenisasi juga terjadi di sini, Kristen Katolik yang dibawa oleh pendatang dari Sintang lebih muda diterima karena bersifat fleksibel dalam mengakomodasi budaya, berbeda dengan Kristen protestan yang cenderung berwarna puritan dan bertujuan memurnikan ajaran-ajaran Kristen tanpa tercampur dengan budaya lokal.

Tradisi Islam yang berkembang di Semabi dan terus eksis hingga kini antara lain: Ziarah Makam; tahlilan kamatian setiap malam ketujuh, kedua puluh lima, empat puluh, dan keseratus hari; tadarrus alquran, majelis taklim ibu-ibu, dan lain sebagainya. Kegiatan Majelis Taklim dan Maulid Al-Barzanji Tradisional (MTMAT) juga aktif di Semabi. Dalam kegiatan Maulid Nabi di desa Semabi, kegiatan ini dipimpin oleh H. Abdul Bakar dan merupakan acara wajib dalam rangka

\footnotetext{
166 Af'idatul latifah, turun Melayu: Konstruksi Identitas Orang Dayak Muslim..., h. 80

167 Emusti Rivasintha, dan Karel Juniardi, Pergerseran Nilai-nilai Budaya dalam Upacara Adat Gawai Dayak ditinjau dari Sosial Ekonomi Masyarakat Kota Pontinak dalm jurnal Sosial Horizon, Vol. 04, No. 1 (2017), h. 5
}

168 Wawancara dengan pak Jamri, 6 September 2019 
meningkatkan rasa cinta dan meneladani nabi Muhammad SAW. Ia berpesan agar masyarakat Semabi tidak mudah terprovokasi dengan kelompok yang tidak bertanggung jawab dan ingin merusak pelaksanaan Maulid nabi...169

Kondisi rukun dan saling menghargai antar-warga Semabi ini didasarka pada lima pilar harmoni, yaitu: (1) etnisitas. Pilar ini membentuk suatu suku bangsa berdasarkan kesamaan norma, nilai, kepercayaan, simbol, dan praktik budaya yang dimiliki bersama berdasarkan garis keturunan dan nenek moyang yang sama; (2) Lokalitas, yaitu semangat saling merangkul antarwarga, baik pribumi maupun pendatang sebagai penduduk desa Semabi Kalimantan Barat. Karena dari sejarahnya saja terdapat dua varian penduduk Kodah (Semabi, sekarang) yaitu Dayak Longkam (pribumi), dan Dayak Tungao Sosat (pendatang);

(3) trust/kepercayaan. Islam di Indonesia identik dengan toleransi, moderasi dan pluralism. ${ }^{170}$ Toleransi dalam interaksi kebaragamaan yang dilandasakan pada sikap saling menghormati dan menghargai antar pemeluk agama; beragama sesuai dengan esensi dan luwes di tengah kondisi masyarakat yang beragam. Toleransi beragama ditampilkan dengan kebebasan beragama bagi warga Dayak maupun pendatang yang mendiami Kalimantan Barat di desa Semabi Kabupaten Sekadau. Pengaruh beragamnya agama tidak mengganggu hubungan warga kerena sebuah keyakinan bagi mereka adalah pilihan mereka sendiri.

Sementara berbicara tentang penyebaran Islam, misionaris Kristen juga berjalan massif. Salah satu daerah yang menjadi tujuan misionaris adalah daerah Nanga Mahab, sebuah kecamatan yang terletak di kabupaten Sekadau. Namun perpindahan agama tidak menyebabkan kehidupan masyarakat Dayak Senganan di Semabi berubah. Hampir semua adat istiadat lama masih dilakukan, kecuali yang menggunakan ritual yang dilarang oleh Islam maka itulah yang ditinggalkan, atau memoles ritual adat lama dengan memberikan sentuhan Islam, seperti upacara menghanyutkan sedekah bumi ke sungai diganti dengan syukuran di tanah lapang yang dihadiri oleh seluruh masyarakat.

(4) Aktor/ketokohan, pengaruh tokoh adat dan muballigh atau pembawa misi agama. Baik pribumi maupun pendatang yang tinggal di Semabi, tentunya tidak terlepas dari pengaruh temenggung adat dan tokoh-tokoh adat lainnya yang komposisinya berasal dari agama yang berbeda. Toleransi ini dimungkinkan oleh watak Islam yang digunakan di Semabi dilakukan dengan pendekatan damai dan keramah-tamahan. Penyebaran agama seperti ini tentu saja didorong oleh misi membawa kedamaian, keselamatan, dan kesejahteraan bagi seluruh alam. Sementara itu, penggunaan identitas sosial bagi masyarakat muslim juga berkontribusi terhadap sikap toleransi di Semabi. Sebagaimana sudah dinyatakan, Senganan adalah istilah untuk menunjuk warga Dayak yang telah beragama Islam, namun tetap dianggap sebagai Dayak Senganan, bukan sebagai Melayu seperti yang terjadi di banyak tempat di Kalimantan Barat.

(5) keterbukaan. Kesadaran berbudaya mendorong seseorang untuk bersikap saling menghargai, memahami, dan mengerti akan adanya perbedaan-perbedaan yang ada. Sehingga, pergumulan identitas tidak menimbulkan benturan yang mengarah pada perpecahan.

\section{Dakwah Harmoni dengan Identitas Baru (New Identity)}

Transformasi identitas baru yang terjadi di Semabi menyentuh tiga sisi, yaitu: pertama, Histori. Dilihat dari sejarahnya, ada dua varian sub suku Dayak, antara lain (1) Dayak Longkam, suku ini tinggal di bukit yang letaknya lebih tinggi dari dataran Semabi, dengan mayoritas penduduk beragama Kristen; (2) Dayak Tungao Sosat, suku ini berasal dari Sintang yang menyebar di sekitar daerah Longkam dan Semabi, kata 'sosat' atau 'sesat' disini bukan sesat dalam hal ajaran, akan tetapi istilah yang digunakan untuk menyebut penduduk Sintang yang menyebar untuk melangsungkan kehidupan, mereka tidak disebut Dayak Longkam karena berstatus sebagai pendatang. Istilah 'Senganan' merupakan transformasi identitas (identitas

169 Arafah, Meneladani Rasulullah, MTAMT Peringati Maulid di Semabi (Desember 01, 2018), dalam www.laduni.id, diakses pada 08 September 2019

${ }^{170}$ Zachary Abuza, Political Islam and Violence in Indonesia, ed. Sumit Ganguly (USA: Routledge: 2007), 1 
baru) bagi penduduk Dayak Longkam muslim yang mulanya beragama Kristen. Mereka tidak menghilangkan identitas lama, yaitu Longkam. ${ }^{171}$

Kedua, Konsep transformasi identitas yang terjadi di Semabi merujuk pada perubahan bentuk identitas dengan tidak meninggalkan unsur lamanya sehingga warisan leluhur tetap dapat terwariskan dengan beberapa modifikasi. H. Abu Bakar ${ }^{172}$ menjelaskan bahwa warga Dayak Semabi dinaungi dalam satu atap majelis yang disebut dengan MABM (Majelis Adat Budaya Melayu). ${ }^{173}$ Penduduk yang telah memeluk Islam di Semabi tidak meninggalkan identitas kedayakannya, mereka menyebut diri sebagai Dayak 'Senganan'. Istilah 'Senganan' berasal dari kata 'kanan' yang diartikan peralihan dari kiri ke kanan, yaitu dengan jalan memeluk agama Islam. Meskipun demikian, tidak semua penduduk muslim Semabi menggunakan identitas Dayak Senganan, generasi (muda) yang berusia 40 tahun ke bawah menyebut diri mereka sebagai Senganan untuk menghapus stigma negatif yang menyebut Dayak sebagai non-Muslim dan lekat dengan citra animis. Dalam hal ini, Senganan dianggap sebagai sebuah kode untuk mempersatukan Islam. ${ }^{174}$

Ketiga, Tradisi. Pola interaksi Islam dengan budaya lokal di Semabi ditampilkan dengan memoles ritual "ngantar buah pulang" dengan menggelar tasyakuran di jalan desa dan menggati mantra-mantra dengan bacaan doa kepada Allah SWT. Ritual "ngantar buah pulang" merupakan bentuk upacara syukur warga Dayak setelah panen raya. Bahkan, setiap kali pohon durian berbuah, maka 3 dari sepuluh pohon durian yang berbuah pertama harus disedekahkan agar mendapatkan berkah dan panen melimpah. ${ }^{175}$

Selain itu, sebelum Islam masuk di Semabi (Kodah), konon terdapat budaya 'berburu kepala untuk mahar nikah'176 sebagai sesembahan kepada nenek moyang. Tradisi ini dianggap sebagai kewajiban agar mereka (yang mau menikah) terhindar dari bahaya, menjadi suatu bentuk kebanggaan, simbol kekuasaan, dan bentuk kejantanan diri. Hingga kini, tradisi seperti itu sudah tidak berlaku dan kemudian diganti dengan 'syarat Muallaf' bagi pemuda non-muslim luar Semabi yang ingin menikahi perempuan muslim desa Semabi. 177

Identitas lainnya yang mengalami transformasi adalah dalam hal simbol. identitas etnik ini antara lain peralatan perang berupa 'talawang'178 atau perisai suku dengan hiasan ukiran yang mencirikan kebudayaan Dayak. Ukiran talawang memiliki daya magis yang mampu membangkitkan semangat serta memberi kekuatan bagi yang menyandang. Pada umumnya, talawang bermotif burung 'tinggang' dan 'kamang', yaitu burung yang dianggap suci dan juga perwujudan roh dari nenek moyang. Aksesoris ini pada mulanya digunakan sebagai perlengkapan perang, namun dewasa ini talawang lebih beralih fungsi sebagai pelengkap dalam tari-tarian, uniknya motif talawang yang ada di Semabi tidak hanya bermotif burung tinggang dan kamang, ada sentuhan dua huruf NU (nahdlatul ulama) familiar yang ditulis di antara motif leluhur.

Modifikasi seperti ini sesungguhya mencerminkan sisi cair sebuah identitas. Motif tinggang dan kamang sebagai simbol yang melekat dan beku menurut konsep identitas Dayak ternyata mengalami pencairan. Pencairan ini memiliki dampak yang positif bagi komunitas lain, yaitu Dayak

\footnotetext{
171 Wawancara dengan Bang Aang Junaidi, (35 th) seorang penambang emas yang menjadi temenggung muda Dayak Senganan. Ia bertugas melestarikan budaya/adat Kodah (Senganan) di dusun Semabi, serta mengkoordinir segala kegiatan yang berkaitan dengan adat setempat dengan kerjasama bersama pemerintah desa.

172 H. Abu Bakar adalah seorang pengurus Majelis Adat Budaya Melayu, berusia 70 tahun (wawancara dilakukan pada 6 September 2019)

173 Secara umum, MABM dikenal sebagai organisasi yang mewadahi nilai-nilai mulia kebudayaan Melayu.

174 Wawancara dengan H. Abu Bakar 70 th, Pengurus Majelis Adat Budaya Melayu, (6 September 2019)

175 Wawancara dengan Bang Aang Yuniarto, Penambang Emas, secara struktural menjabat sebagai Temenggung Adat Formal Dusun Semabi, (6 September 2019)

176 Peninggalan sejarah berupa tempurung kepala manusia kemudian dikumpulkan sebagai situs sejarah di rumah 'lanan' maupun digantungkan pada 'tiang sandung' atau kayu besi di daerah Landau Kodah.

177 Wawancara dengan pak Jamri, (6 September 2019)

178 Talawang terbuat dari kayu ulin atau kayu besi, dengan bentuk persegi panjang dan dibuat runcing pada bagian atas dan bawah. Panjangnya sekitar 1-2 meter dengan lebar maksimal $50 \mathrm{~cm}$.
} 
yang memeluk Islam memiliki identitas baru sebagai muslim, namun tidak kehilangan identitas lama sebagai bagian dari etnis ini.

\section{F. Kesimpulan}

Identitas merupakan ciri yang dimiliki seseorang atau sesuatu sebagai pengenal atau pembeda antara satu dengan yang lain Konsep transformasi identitas yang terjadi di Semabi merujuk pada perubahan bentuk identitas dengan tidak meninggalkan unsur lamanya sehingga warisan leluhur tetap dapat terwariskan dengan beberapa modifikasi.

Dari sisi religiusitas, penduduk pribumi telah mengalami proses transformasi identitas yang semula berkeyakinan pada kekuatan ruh menjadi berketuhanan; transformasi yang lain berupa identifikasi muslim-non-muslim dari Longkam menjadi Dayak Senganan, meskipun menggunakan identitas baru namun identitas lama tidak hilang bagi penduduk Dayak yang telah masuk Islam di desa Semabi, Sekadau Hilir, Sekadau, Kalimantan Barat.

Dalam hal tradisi, ritual "ngantar buah pulang" diganti dengan menggelar tasyakuran di jalan desa dan menggati mantra-mantra dengan bacaan doa kepada Allah SWT. Selain itu, sebelum Islam masuk di Semabi (Kodah), konon terdapat budaya 'berburu kepala untuk mahar nikah' sebagai sesembahan kepada nenek moyang. Hingga kini, tradisi seperti itu sudah tidak berlaku dan kemudian diganti dengan 'syarat Muallaf' bagi pemuda non-muslim luar Semabi yang ingin menikahi perempuan muslim desa Semabi.

Kunci kerukunan antar-warga didukung dengan kekuatan harmonisasi serta peran kesadaran bersama untuk hidup berdampingan menjadi tolak ukur harmonisasi yang melekat pada diri warga pribumi maupun pendatang di Semabi. Dalam perspektif dakwah harmoni yang dibangun oleh para elit agama dan elit budaya lokal, inilah model dakwah transformatif yang berbasis pada tradisi.

\section{Daftar Pustaka}

Shamsul, A. B. "Identiti dan Etnisiti: Tinjauan Teoretis", dalam Yusriadi dan Haitami Salim, ed, Prosiding Kolokium Dayak Islam di Kalimantan Barat. Pontianak: STAIN Pontianak-FUIMABM, 2001.

Abuza, Zachary. Political Islam and Violence in Indonesia, ed. Sumit Ganguly. USA: Routledge: 2007.

Ahyat, Ita Syamtasiyah. Dinamika dan Pengaruh Budaya Melayu di Kalimantan Barat, makalah dipresentasikan pada "Prosiding the $4^{\text {th }}$ Conference on Indonesian Studies: Unity, Diversity, and Future."

AR, Ahmad Muthohar. Islam Dayak: Diaektika Identitas Dayak Tidung di Kalimantan. Semarang: Fatawa Publishing.

Arafah, Meneladani Rasulullah, MTAMT Peringati Maulid di Semabi (Desember 01, 2018), dalam www.laduni.id, diakses pada 08 September 2019

Berger, Peter L. \& Thomas Luckmann, .The Social Construction of Reality, dalam Hasan basari (terj), Tafsir Sosial atas kenyataan: Risalah tentang Sosiologi pengertahuan. Jakarta: LP3ES, 1990.

BPS-Statistic Indonesia, Statistik Indonesia: Statistical Yearbook of Indonesia 2018

Freese, Lee and Peter J. Burke, Person. Identities, and Social Interaction. London: JAI Press, t.t.

Geertz, Cliffort. The Interpretation of Cultures: Selected essays. USA: Basic Books, Inc., Publishers, 1973.

Hall, Stuart and Paul Du Gay, Ed. Questions of Cultural Identity. London: Sage Publication, 2003. 
Hermansyah. Islam dan Toleransi Beragama dalam Masyarakat Muslim Kanayatn Dayak di Kalimantan Barat, dalam jurnal Islamica, Vol. 7, N. 02, 2013.

Hitchoock, Michael and Victor T. King. Tourism in South East Asia. New York: Roudledge, 1993.

Kurniyanto, Yuni Sekadau targetkan Swasembada Beras, (Januari 3, 2019), dalam https://equator.co.id diakses pada 08 September 2019

Lahajir. Etnoekologi Perladangan Orang Dayak Tunjung Linggang: Etnografi Lingkungan Hidup di Dataran Tinggi Tunjung. Yogyakarta: Galing Printika, 2001.

Lathifah, Af'idatul. Turun Melayu: Konstruksi Identitas Orang Dayak Muslim di Desa Kuala Rosan Kalimantan Barat, dalam jurnal Endogami: Jurnal Ilmiah Kajian Antropologi, Vol. 2 No. 1. Desember 2018.

Makmur, Ade, ed. Kearifan Lokal di Tengah Modernisasi. t.k: Puslitbang Kebudayaan RI, 2011.

Mardimin, Johanes ed. Jangan tangisi Tradisi: Transformasi Budaya menuju Masyarakat Indonesia Modern. Yogyakarta: Kasinius, 1994.

Marjanto, Damardjati Kun. Kaharingan: Perjuangan Masyarakat Adat Dayak ngaju di Kabupaten Kotawaringin Timur, Dahulu dan Sekarang, dalam Ade Makmur, ed, Kearifan Lokal di Tengah Modernisasi. t.k: Puslitbang Kebudayaan RI, 2011.

Martono, Nanang. Sosiologi Perubahan Sosial: Perspektif Klasik, Modern, Postmodern, dan Psikolonial, edisi Revisi, Cet. 4. Jakarta: Rajawali Press, 2016.

Masykur, Anis. Resistensi atas Islamisasi di Kerajaan Kutai kartanegara, dalam Jurnal Istiqro', Vol 1. Jakarta: Depag RI, 2007.

Rivasintha, Emusti dan Karel Juniardi, Pergerseran Nilai-nilai Budaya dalam Upacara Adat Gawai Dayak ditinjau dari Sosial Ekonomi Masyarakat Kota Pontianak, dalam jurnal Sosial Horizon, Vol. 04, No. 1, 2017.

Salim, Agus. Teori dan paradigm Peneliatian Sosial: Buku Sumber untuk Penelitian, Edisi 2. Yogyakarta: Tiara Wacana, 2006.

Singarimbun, Masri. Penduduk dan Perubahan. Yogyakarta: Pustaka Pelajar, 1996.

Spardley, James P. Metode etnografi, Terj. Misbah Elizabeth. Yogyakarta: Tiara Wacana, 1997.

Turner, Jonathan H. Handbook of Sociological Theory. New York: Springer, 2006.

Wahono, Francis. Gerakan Pemberdayaan Pancur Kasih. Pontianak: ID, 2013.

Yusriadi. Identitas Dayak dan Melayu di Kalimantan Barat, dalam jurnal Handep, Vol. 1, No. 2, Juni 2018. 